\title{
Menstrual cramps: A new therapeutic alternative care through medicinal plants
}

\author{
Andrieli Daiane Zdanski de Souza*, Marjoriê da Costa Mendieta, \\ Glaucia Fragoso Hohenberger, Marcelo Melo Silva, Teila Ceolin, Rita Maria Heck
}

Nursing, Federal University of Pelotas, Pelotas, Brazil; ${ }^{*}$ Corresponding Author: andriele zdanski@hotmail.com

Received 23 April 2013; revised 25 May 2013; accepted 17 June 2013

Copyright (C 2013 Andrieli Daiane Zdanski de Souza et al. This is an open access article distributed under the Creative Commons Attribution License, which permits unrestricted use, distribution, and reproduction in any medium, provided the original work is properly cited.

\begin{abstract}
The study aims to know the medicinal plants used by farming families of communities in four municipalities of the south region of RS for the relief of menstrual cramps. It is a descriptive study that analyzed qualitative data. The subjects were 19 farmers from Canguçu, Arroio do Padre, Morro Redondo and Pelotas. Data were collected from January and May the 2009, through semi-structured interviews. Eight plants used for relieve menstrual cramps were cited. This research showed that the popular knowledge of farmers is consistent, in $100 \%$, with the search made in the scientific literature. It is evident that the plants Apium sp., Plectranhus sp., Cinnamomum sp., Chenopodium ambrostoides, Origamun sp., Petroselimum crispum have evidence in the scientific literature, showing that the individuals in this study use the medicinal plants suitable for their purpose.
\end{abstract}

Keywords: Medicinal Plants; Nursing; Colic; Complementary Therapies

\section{INTRODUCTION}

The Brazilian Unified Health System (SUS, as per its acronym in Portuguese) was created in Brazil with the promulgation of the Federal Constitution of 1988, making free access to healthcare the right of every citizen. Implementation of the SUS was based on laws 8.080 and 8.142 of 1990, with the principles of comprehensiveness, universality and equity, and the directives of hierarchy and community participation [1].

Many policies were created and implemented through the SUS, such as the National Policy for Comprehensive Care to Women's Health (PNAISM, as per its acronym in
Portuguese) and the National Policy for Integrative and Complementary Practices (PNPIC, as per its acronym in Portuguese). Medicinal plants (phytotherapy) are a part of complementary therapies, as well as acupuncture, thermalism (crenotherapy), homeopathy and anthroposophic medicine [2].

These have a comprehensive focus in relation to the individual, in which care is focused on the lifestyle of the human being, his/her social relations, with the construction of a bond between the professional and the patient, aiming for comprehensive care. It is perceived that the use of such therapies is principally backed by empirical knowledge, and occurs based on the proof seen during the proactive of one or more of these activities [2,3].

Medicinal plants are primarily used in the informal health system for the treatment and prevention of illnesses, as well as the promotion of the health of individuals and families. Among the plants used, those for the alleviation of menstrual cramps (primary dysmenorrhea) are recommended.

Dysmenorrhea, also called menstrual pain syndrome or menalgia, is defined as pre-menstrual pelvic pain, with or without systemic symptoms. This can be classified as primary or secondary depending on its etiology. It is considered to be primary dysmenorrhea when underlying organic problems exist. In secondary dysmenorrhea there is the presence of triggering organic diseases [4].

Primary dysmenorrhea is characterized clinically as a colic pain in the lower abdomen region during the beginning of menstruation, which may continue for several days, in the absence of any pelvic pathology. Its intensity varies may or may not occur concomitantly with other symptoms such as vomiting, diarrhea, tiredness, headache or even fainting [4].

Primary dysmenorrhea is related to ovulation cycles, and its occurrence is higher during this period. The majority of symptoms can be explained by the action of 
prostaglandin, in particular PGF2 $\alpha$, which is present in the menstrual fluid, and which determines abnormal uterine activity, reducing the flow of blood to the uterus and increasing the sensibility of the nociceptors. Women with primary dysmenorrhea show high levels of prostaglandin in the endometrium and menstrual blood, showing significant improvements in the symptoms as prostaglandin levels are reduced. Thus the inhibition of the production of prostaglandins in the endometrium with the use of non-steroid anti-inflammatories has been shown to be an effective treatment [4].

In this sense, to alleviate the symptoms of menstrual colic, in addition to allopathic medication, complementary therapies also exist that may assist in this process, helping this group in the promotion of health. As a consequence, this study seeks scientific evidence, and through this to provide health professional and the community with knowledge, and in this way to implement medicinal plants as a new resource in health care, in order to promote health.

This article has the objective to identify the medicinal plants used to alleviate menstrual colic by family farmers in communities of four municipalities in the southern region of the Brazilian state of Rio Grande do Sul.

\section{MATERIALS AND METHODS}

This is a descriptive study analyzing qualitative data, and is part of the Project for bioactive plants for human use by families of sustainable farmers in the Southern region of Rio Grande do Sul, developed by the College of Nursing at the Federal University of Pelotas and the Temperate Climate division of the Empresa Brasileira de Pesquisa Agropecuária (EMBRAPA) [Brazilian Agricultural Research Corporation], with funding from the Conselho Nacional de Desenvolvimento Científico e Tecnológico (CNPq) [National Council for Scientific and Technological Development].

The population studied was composed of 19 individuals, both men and women which were farmers living in the rural areas of the municipalities of Pelotas, Morro Redondo, Canguçu and Arroio do Padre, in the Southern region of Rio Grande do Sul, Brazil [5]. The participants were selected through indication of these individuals as knowledgeable about medicinal plants by the coordinator of the farmers' market association, and was based on the snowball sampling methodology [6].

This methodology is based on a non-probabilistic sampling that defines a chain of informants; that is, respondents identified for the research indicate other respondents until a sufficient sample is attained [6]. Data collection occurred at the homes of the families during the period from January to May of 2009.

A semi structured interview, participant observation and photographic record of the medicinal plants were used as instruments. The plants collected and photographed were identified by a botanist associated with Embrapa Temperate Climate. According to the chosen methodological approach, data were analyzed through the following stages: description of the context of the study subjects; elaboration of the profile of the interviewees; transcription of the interviews and field journal reading. Afterwards, data were classified into four themes: knowledge transmission; flow of the knowledge related to medicinal plants; health comprehension and knowledge loss regarding the plants. At the final analysis, data were confronted against the theoretical referential. In this article will be addressed about the medicinal plants mentioned in the treatment of menstrual cramps. In regard to analysis of the data, the information pertinent to the farmers' knowledge about the medicinal plants used to alleviate menstrual colic was organized in a frame (scientific name, Family and popular name of each plants and use mentioned by the subjects). Later the information from the table was compared with pharmacological and phytochemical studies.

Based on the information from the research participants, literature reviews were performed in books on the topic, and studies available in Literatura Latino-Americana em Ciências da Saúde (LILACS) (Latin American Literature on Health Sciences), Scientific Electronic Library Online (SciELO) and PubMed (Public Medline) about the medicinal plants cited with effects associated to the alleviation of menstrual colic symptoms. The searches were done by the scientific name of each medicinal plant cited. The project adhered to the research norms involving human beings, according to Resolutions 196/96, and received approval from the Research Ethics Committee of the Medical School of the Federal University of Pelotas (072/2007).

\section{RESULTS}

The age range of the participants varied from 12 to 90 years, with the Catholic and Lutheran religions predominating. In regard to education level, three participants were illiterate, 21 had an incomplete primary education level, four had a complete primary education level, and three of the youngest members were attending secondary education.

The participants interviewed cited 196 medicinal plants; of these, only six plants were referenced as alleviating menstrual colic, and these are described in Frame 1.

\section{DISCUSSION}

Brazil has ample cultural and ethnic diversity, with a considerable accumulation of traditional knowledge and technologies, and often the only [medical] resource that a 
population has access to are medicinal plants [7].

In this perspective, medicinal plants are a complementary way to improve health, as they are easy to access and economically viable in comparison to allopathic medicine. In this context, some research is being developed about plants to alleviate menstrual colic [8].

Scientific studies proving the anti-inflammatory and analgesic effect were found for the six plants cited, showing that the popular knowledge of those interviewed for this study is in accordance with the literature. It is known that anti-inflammatory drugs, especially the nonsteroidal anti-inflammatory medicines (NSAIMs), are used to alleviate menstrual colic because they are antagonists to the prostaglandins, which are in increased production during menstruation, and this is believed to be the cause of pain in cases of primary dysmenorrheal [9].

One experimental trial done with mice showed that the extract from the leaves of Apium graveolens has antiinflammatory and sedative actions $[9,10]$. Due to the presence of flavonoids, Plectranthus amboinicus, is being used as an anti-inflammatory medicine [8]. One experimental trial showed the possibility that the hydroalcoholic extract of this plant has analgesic activity [11].

The oil extracted from the branches of the Cinnamomum osmophloeum plant have anti-inflammatory activity [12]. However, toxicology trials performed with high doses demonstrated that the oil of this plant caused irritation of the mucous membranes and provoked hematúria [13].

The Chenopodium ambrosioides has as a chemicalcomponent ascaridole, composed of the cineol (eucalyptol), which has anti-inflammatory action [14]. Pharmacological studies proved that Origanun vulgare shows anti-inflammatory potential through in vitro tests [15], as well as analgesic potential [16]. Another species, Origanunsyriacum also had its anti-inflammatory activity proven through tests on rats [17].

The roots and seeds of the Petroselinum crispum are indicated for problems and menstrual colic because they have a relaxing effect on smooth muscle and an analgesic effect [8].

Pharmacology studies that indicate the dosing that should be used for each plant were not found, proving the need for increased studies on this theme, since menstrual colic is a problem that occurs in the majority of women.

In this perspective, through implementation of the PNPIC, increased therapy choices being offered to users of the SUS is taking place, with guaranteed access to medicinal plants and services relation to phytotherapy, with safety, efficacy and quality. This health policy is premised on the comprehensiveness of care, and is an important resource that aims to improve health care of the population, as well as social inclusion [2].

Nursing is a profession that can indicate this type of therapy in Brazil, because the Federal Nursing Council of Brazil (COFEn) [18], through Normative Opinion No. 004/95, recognizes that complementary/alternative therapies are practices that mostly originated from Eastern cultures, and are not connected to any type of professional category. According to Resolution (RDC) 197/97 of the COFEn, in order for a nurse to be able to indicate [medicinal plants], s/he needs to be considered a specialist, and must complete a specialization with 360 course hours.

Thus, it is understood that the nurse needs to understand the complexity of the health-disease process, applying integration and consequently promoting the health of the individual through active conversations, seeking to create a connection, and always providing direction about possible complications and how to prevent them [19]. Thus, it is possible to know and value the popular knowledge of the users of health services, inserting this knowledge into healthcare.

Based on the popular knowledge referenced by the farmers in regard to the six medicinal plants indicated for the treatment of menstrual colic, it was concluded that for each one, the knowledge is in accordance with the scientific studies researched.

Frame 1. Medicinal plants used by research participants to alleviate menstrual colic. Rio Grande do Sul, Brazil, 2012.

\begin{tabular}{|c|c|c|c|}
\hline Scientific Name & Family & Popular name ${ }^{*}$ & Use mentioned by the interviewees \\
\hline Apium sp. & Apiaceae & Aipim-da-cólica & Analgesic, to alleviate menstrual colic. \\
\hline Cinnamomum sp. & Laureaceae & Canela (cinnamon) & Alleviate menstrual colic, but toxic in excess. \\
\hline $\begin{array}{l}\text { Chenopodium } \\
\text { ambrosioides }\end{array}$ & Chenopodiaceae & Erva-santa-maria & Alleviate menstrual colic. \\
\hline Origanun sp. & Labiatae & Manjerona (marjoram) & Alleviate menstrual colic. \\
\hline Petroselinum crispum & Apiaceae & Salsa (parsley) & Alleviate menstrual colic. \\
\hline
\end{tabular}

*In Brazilian portuguese with English popular names, if available; Source: project "bioactive plants for human consumption by sustainable family farmers in the Southern region of Rio Grande do Sul, 2009. 


\section{FINAL CONSIDERATIONS}

The need for more clinical trials to be done in regard to medicinal plants used to alleviate menstrual colic is observed, emphasizing that the knowledge of the participants of this research is conducive to the scientific literature review, which proves that the majority uses medicinal plants appropriately.

It is of utmost importance that the policies existing in the SUS, for example the National Policy for Comprehensive and Complementary Practices (PNPIC), are successfully put into practice, because they were created to provide comprehensive service to multidimensional beings: physiological, psychological, social and spiritual, living in a family and in the community, in this case, through the use of medicinal plants and phytotherapies.

It is fundamental that nursing is constantly updated in order to meet the demand of the community. These studies highlight the importance of the nurse and other health professionals to encourage the use of medicinal plants that have proven effects, remembering that this should be a relationship based on respect for the other, considering the culture of each location and principally not forgetting that each subject is a unique being, with his/her own particularities.

\section{REFERENCES}

[1] Paim, J.S. (2009) What is SUS. Editora Fiocruz, Rio de Janeiro.

[2] Ministry of Health (2006) National policy on complementary and integrative practices in SUS (PNPIC SUS). Ministry of Health, Brazil.

[3] Ceolin, T. (2009) Knowledge about medicinal plants among ecological farmers in southern Rio Grande do Sul. Dissertation, Federal University of Pelotas, Pelotas.

[4] Brazilian Federation of Societies of Obstetrics and Gynecology (FEBRASGO) (2013) Dysmenorrhea. Project guidelines-Brazilian Medical Association and Federal Council of Medicine.

http://www.bibliomed.com.br/diretrizes/pdf/dismenorreia. pdf

[5] Ceolin, T., et al. (2011) Medicinal plants: Knowledge transmission in families of ecological farmers in souther Rio Grande do Sul. Revista da Escola de Enfermagem, 45, 47-54. http://www.scielo.br/pdf/reeusp/v45n1/en_07.pdf doi:10.1590/S0080-62342011000100007

[6] Baldin, N. and Munhoz, E.M.B. (2011) Snowball (ice ball): A methodological technique for environmental education research community. In: Annals of the X National Congress of Education-Educere, 329-341.

[7] Ministry of Health (2005) National policy on natural medicine and complementary practices-PMNPC. Ministry of Health, Brazil.

[8] Lorenzi, H. and Matos, F.J.A. (2008) Medicinal plants of Brazil: Native and exotic. Instituto Plantarum, Nova Ode- ssa.

[9] Smeltzer, S.C., Bare, B.G., Hinkle, J.L. and Cheever, K.H. (2009) Brunner \& suddarth: Treaty of medical surgical nursing. Guanabara, Rio de Janeiro.

[10] Mencherini, T., Cau, A., Bianco, G., Loggia, R.D. and Aquino, R.P. (2007) An extract of Apium graveolens var. dulce leaves: Structure of the major constituent, apiin, and its anti-inflammatory properties. Journal of Pharmacy and Pharmacology, 21, 891-897. doi:10.1211/jpp.59.6.0016

[11] Chiu, Y.J., Huang, T.H., Chiu, C.S., Lu, T.C., Chen Y.W., Peng, W.H., et al. (2012) Analgesic and antiinflammatory activities of the aqueous extract from Plectranthus amboinicus (Lour). Spreng. Both in vitro and in vivo. Evidence-Based Complementary and Alternative Medicine, 2012, 1-11.

http://www.hindawi.com/journals/ecam/2012/508137/ doi:10.1155/2012/508137

[12] Tung, Y.T., Chua, M.T., Yang, S.W. and Chang, S.T. (2008) Anti-inflammation activities of essential oil and its constituents from indigenous cinnamon (Cinnamomum osmophloeum) twigs. Bioresource Technology, 99, 39083913.

http://web.nchu.edu.tw/pweb/users/taiwanfir/research/989 3.pdf doi:10.1016/j.biortech.2007.07.050

[13] Simões, C.M.D.O., Schenkel, E.P., Gosmann, G., Mello, J.C.P.D., Mentizm L.A. and Petrovick, P.R. (2007) Pharmacognosy: From plant to medicament. Editora da UFRGS/ Editora da UFSC, Porto Alegre/Florianópolis, Brazil.

[14] Matos, F.J.A. (2002) Living pharmacies: System utilization of medicinal plants designed for small communities. Editora UFC, Fortaleza.

[15] Ocaña-Fuentes, A., Arranz-Gutiérrez, E., Señorans, F.J. and Reglero, G. (2010) Supercritical fluid extraction of oregano (Origanum vulgare) essentials oils: Anti-inflammatory properties based on cytokine response on THP-1 macrophages. Food and Chemical Toxicology, 48, 15681575. doi:10.1016/j.fct.2010.03.026

[16] Arzi, A., Aghel, N., Khorasgani, Z.N. and Motahari, M. (2009) The study of analgesic effect of hydroalcoholic extract of Origanum vulgare in rat by formalin test. Toxicology Letters, 189, 105-115. doi:10.1016/j.toxlet.2009.06.341

[17] Awaad, A.S., El-meligy, R.M., Qenawy, A.S., Atta, A.H. and Soliman, G.A. (2011) Anti-inflammatory, antinociceptive and antipyretic effects of some desert plants. Journal of Saudi Chemical Society, 15, 367-373. http://ipac.kacst.edu.sa/eDoc/2011/191580_1.pdf doi:10.1016/j.jscs.2011.02.004

[18] Federal Council of Nursing (COFEn)/Brazil (2013) Code of ethics of nurses. Resolution COFEN 311/2007. http://novo.portalcofen.gov.br/wp-content/uploads/2012/0 3/resolucao_311_anexo.pdf

[19] Wosnes, K.R., Locatelli, K., Noguez, P.T. and Ceolin, T. (2010) The knowledge of diabetic patients on feet care. Enfermería Comunitaria, 6, 8 p. 